Irish Math. Soc. Bulletin

Number 73, Summer 2014, 53-55

ISSN 0791-5578

\title{
Siddartha Sen: The Joy of Understanding and Solving Problems: A Guide to School Mathematics, Lulu.com (USA), 2012.
} ISBN:978-1-291-42495-9, EUR 36.75, 607 pp.

\author{
REVIEWED BY MICHAEL BRENNAN
}

The Joy of Understanding and Solving Problems - A Guide to School Mathematics makes some new inroads into school mathematics but few inroads into joy. Siddartha Sen has a gift for bringing innovative examples and fresh motivations to old and well-worn topics, but in his stout-hearted ambition to present the whole of school mathematics, and more besides, in an expository fashion in a single volume, the novelty that should be at the heart of joy soon drains away. An Irish reader will notice that some of the material, as much as 100 pages of the 600 in the book, including vectors, conics and group theory, is no longer on any second-level maths syllabus.

The book aims high. In a long preface on the nature of maths and maths learning, the author declares his intention that the book should implement, embody perhaps, the idea that (quoting mythologist Joseph Campbell) a civilisation is on the rise when there is "integrity and cogency in [that civilisation's] supportive canons of myths, for not authority but aspiration is the motivator, builder and transformer of civilisation".

Maintaining such an ideal among the nuts and bolts of a didactic course in school mathematics was always going to be challenge, and despite the sprinkling of novel motivational examples, the book overall does not escape its own gunfire: "mathematics is taught in schools as a collection of rules for solving certain examination problems". Most of the methods, apart from the most elementary, where the derivation can be explained, are introduced conventionally by rules.

While Sen's aspiration is that the senior school student, at whom he

Received on 18-5-2014. 
says the book is aimed, will hear that "mathematics is an enjoyable human activity created by people with great imagination who have a passion to solve problems and find patterns", normal 16-year olds will worry about whether they have enough imagination to create mathematics, and if not, how they fit in.

Long chapters of worded exposition mean that this is not a textbook. In places it justifies the choice of topics on a school syllabus, in other places it merely rehearses the material. How a second-level student would use it is not clear. Good maths students could refer to it for reassurance or further study, but this is hardly its purpose: the students that inspirational books want to capture are the weaker ones, those who would love to be inspired.

Sen works through Leaving Certificate Euclidean Geometry in a verbalising manner, where a school text would be terse. Verbalising does not always mean clarifying. In the theorem about corresponding sides in similar triangles being proportional, the proof moves from " $\lambda^{2}\left(B X^{2}+A X^{2}\right)=F Y^{2}+A Y^{2}$ " to "This equation has to hold as an identity. Thus $A Y=\lambda A X, F Y=\lambda B X$ ". The normal 16-year old would be tempted to learn this passage by heart. When dealing with the Geometry it might have been better to have focussed on how the student will meet the new demand by Project Maths: that he/she be able to "use the following terms related to logic and deductive reasoning: is equivalent to, if and only if, proof by contradiction".

Siddartha Sen's book should be reduced and rewritten. It does not have to start with addition of integers - some threshold can be assumed. And rather than attempting to compete exhaustively with school texts, it should focus on a few interesting ideas about pattern and structure and mathematical inquiry. That would give it a chance to become the inspirational, joyful handbook that Sen intended. But in the rewriting, a lot needs to change. The book is littered with editorial typos, and these intrude on the mathematics. The main page on quaternions is full of errors $(j k=i$, then $j k=-i, \ldots, i k=j \ldots)$. There is repetition of topics, and when this happens the book does not reference itself. 
One of the potentially best chapters in the book, "Using Mathematics", starts on page 534. Apart from explaining, again, how to calculate $5-3+1$, and the rules of fractions, both covered 500 pages earlier, it contains a section on Maths Muscle Building, where Sen seeks to use the algebra that has been learned, though principally to solve algebraic problems. This idea could be expanded to include mathematical modelling for second-level pupils, and the black art of converting a worded problem to a symbolic one teased out and revealed to all, student and teacher alike. Acquiring this art is the biggest challenge facing our second-level maths teachers today.

In hurling counties in Ireland there is the concept of the "makings" of a hurley, a J-shaped plank cut from the lower half and root of a young ash-tree. It looks like a hurley but one could not play with it. Before hand-drills/sanders became household items, a person would reduce the makings to a proper hurley using a spoke-shave. The Joy of Understanding and Solving Problem has the makings of a new type of maths book. The author must take a spoke-shave to it.

Michael Brennan is a Research Associate with the Trinity Irish Art Research Centre (TRIARC) at TCD, examining the structure of motifs in early medieval art. He is a Council member of the Irish Mathematics Teachers Association.

School of Humanitities, Trinity College Dublin

E-mail address: brennamn@tcd.ie 